\title{
Anthropometric characteristics and nutritional status based on body mass index of muslim females in Varanasi
}

\author{
SHAISTA PARVEEN, ARCHANA CHAKRAVARTY AND N.K. AGRAWAL
}

Received: 21.04.2017; Revised: 25.09.2017; Accepted: 11.10.2017

See end of the paper for authors' affiliations SHAISTA PARVEEN

Department of Home science (Food and Nutrition), Mahila Maha Vidhyalaya, Banaras Hindu University, VARANASI (U.P.) INDIA

Email : parveen87shaista@ gmail.com
ABSTRACT : Under nutrition, overweight and obesity of individuals who differ by age and sex are matters of great concern having social and health implications for countries around the world. According to NFHS report (1998-99), based on weight for height index (body mass index), more than one-third (36\%) of women in Uttar Pradesh are undernourished. Health status of women is of great concern in the contemporary world, because of the multiple roles play by women given rise to serious health and nutritional problems. Women are, thus, vulnerable to malnutrition for social and biological reasons. A cross-sectional study was undertaken to determine anthropometric profile and nutritional status based on body mass index (BMI) of muslim females in Varanasi. A total of 220 females (aged 15 - 45years) residing in urban area of Varanasi was studied. Anthropometric profile including height, weight, waist circumference as well as BMI and waist-hip ratio (WHR) were measured. The main aim of the study was to determine their anthropometric characteristics and nutritional status through the assessment of Body Mass Index (BMI) and Waist-Hip ratio. It was found that 35.5\%, 36.8\%, $14.1 \%$ and $13.6 \%$ were under weight, normal, pre-obese (overweight) and obese, respectively on the basis of Asian BMI categorization. On the account of waist-hip ratio, $42.7 \%$ respondents were at high health risk whereas $57.3 \%$ were at low health risk. This study will provide baseline data for further studies on Muslim women in India and will help to plan and implement a comprehensive package for the management of their nutritional status.

KEY WORDS: Nutritional status, Muslim females, Anthropometric characteristics

- HOW TO CITE THIS PAPER : Parveen, Shaista, Chakravarty, Archana and Agrawal, N.K. (2017). Anthropometric characteristics and nutritional status based on body mass index of muslim females in Varanasi. Asian J. Home Sci., 12 (2) : 382-384, DOI: 10.15740/HAS/AJHS/12.2/382-384. 